\title{
Noise Exposure Assessment for University Police Officers during Rifle and Shotgun Qualifications
}

\author{
By Emmanuel Iyiegbuniwe ${ }^{*}$ Alexander Ufelle $e^{\dagger} \&$ Anita Britt ${ }^{*}$
}

Police and other law enforcement officers are routinely exposed to hazardous noise levels during normal working conditions. Occupational noise exposure is a known risk factor for noise-induced hearing loss and other documented non-auditory health effects of significant public health importance. The purpose of this study was to assess noise exposures among a convenient and representative sample of police officers and instructors at a University in Kentucky during routine rifle and shotgun qualifications at an outdoor firing range. The assessment was conducted among 17 police officers and 2 instructors over a period of 3 days in accordance with the requirements of national noise standards (29 CFR 1910.95) stipulated by the United States Occupational Safety and Health Administration (OSHA). We measured both personal and area sound pressure levels using calibrated noise dosimeters and sound level meters. Average personal noise levels during shotgun and rifle qualifications ranged from 74 to $101 \mathrm{dBA}$ and 90 to $101 \mathrm{dBA}$, respectively. The results of area noise measurements for shotgun and rifle ranged from 107 to $121 \mathrm{dBA}$ and 106 to $114 \mathrm{dBA}$, respectively. Without consideration of hearing protection, personal exposures exceeded OSHA's noise standards (i.e., Permissible Exposure Limit of $90 \mathrm{dBA}$ and Action Level of $85 \mathrm{dBA}$, averaged over 8 hours work-shift). The results indicate potential health risks from continuous noise exposures among these police officers and instructors. Recommendations are made for continued adherence to and reinforcement of all elements of OSHA's hearing conservation program.

Keywords: University police officers, Rifle and shotgun qualifications, outdoor firing range, Occupational noise exposure assessment, Hearing conservation program

\section{Introduction}

In the United States, approximately 22 million workers are exposed to potentially damaging noise annually (OSHA 2018). The Occupational Safety and Health Administration (OSHA) estimates that in 2017, American businesses paid over $\$ 1.5$ million in penalties for not protecting their employees from noise. Annually, compensation for worker-related hearing loss disabilities accounted for a huge economic burden of approximately \$242 million (OSHA 2018). A previously published report by the National Institute for Occupational Safety and Health (NIOSH 1998) estimated that 30 million American workers were exposed to hazardous noise each year. The NIOSH report further noted that occupational noise remains one of the most common and significant health hazards among industrial workers. Available research supports the increasing prevalence of higher noise levels in many industrial workplaces (Patel and Ingle 2008). In addition, occupational noise continues to be a critical health and safety issue in the $21^{\text {st }}$ century workplace (NIOSH 1996).Worldwide, it is estimated that $16 \%$ of all hearing losses in adults is attributed to occupational noise and has resulted in an

\footnotetext{
*Director of Public Health \& Associate Professor, California State University San Marcos, USA.

${ }^{\dagger}$ Assistant Professor of Public Health and Social Work, Slippery Rock University, USA.

Environment Air Quality Specialist, Western Kentucky University, USA.
} 
estimated cost of $0.2 \%$ to $2.0 \%$ of the gross domestic products in developed countries (Nandi and Dhatrak 2008). Although there has been some significant improvements towards reducing noise exposure, it still remains a global challenge (Concha-Barrientos et al. 2004).

Noise or unwanted sound, is a very common occupational hazard in the workplace. Sound is "a rapid variation of atmospheric pressure caused by some disturbance of the air" (Royster et al. 2003). Routine exposure to hazardous noise and the prevailing non-adherence to hearing protection remains one of the most common occupational hazards among workers (Bhatt et al. 2017). Individuals of all ages, including children, adolescents, young adults, and older people, can develop noise-induced hearing loss during exposure to intense noise in the workplace, at recreational settings, or at home (Jansen et al. 2009). Excessive and repeated exposures to hazardous noise over an extended period of time, loud impulse sounds, or a combination of both, can lead to noise-induced hearing loss (NIHL) or sensorineural hearing loss (Jansen et al. 2009). NIHL is an irreversible, sensorineural condition that progresses with continued exposure to hazardous noise (Harney et al. 2005). Exposure to excessive noise constitutes a major avoidable cause of permanent hearing impairment and produces hearing loss that far exceed those resulting from the natural aging process or a term referred to as presbycusis (Nandi and Dhatrak 2008). A study by Patel and Ingle (2008) reported that in addition to hearing impairment, occupational exposure to excessive noise also caused non-auditory health effects. Health effects that result from noise generally depend on the exposure level and duration.

NIHL results from repeated exposure to hazardous noise of long durations that cause damage to the hair cells of the cochlea in the inner ear. Tak and Calvert (2008) reported that over $11 \%$ of the United States population was affected by hearing loss and is considered the third-most prevalent condition among older adults (Bogardus et al. 2003). Additionally, NIOSH has stated that NIHL is one of the top ten priority areas for the most critical diseases and injuries requiring research and development activities under the National Occupational Research Agenda. In order to protect American workers from developing permanent heating loss, NIOSH has included NIHL in the list of 21 priority areas of targeted research in the next century. In general, the effects of noise depend on three physical characteristics of sound: amplitude, frequency, and duration.

Sound pressure level is generally expressed in decibels $(\mathrm{dB})$ or as a unit that measures the amplitude of pressure change that produces sound (perceived as loudness). In the United States, occupational noise exposure limits are typically reported in decibels using the A-weighted scale (dBA). As described in 29 CFR 1910.95 , the OSHA standard for occupational exposure to noise stipulates a permissible exposure limit (PEL) of $90 \mathrm{dBA}$ with an exchange rate of $5 \mathrm{dBA}$ as an 8-hour time weighted average (TWA) (OSHA 2003). The OSHA noise standards stipulate that workers exposed to noise levels in excess of the PEL, feasible engineering and administrative controls must be implemented to reduce workers' exposure levels. Furthermore, OSHA standards stipulate that the selection of noise exposure limits must consider two parameters including the maximum acceptable occupational hearing loss (i.e., the fence) and the percentage of the occupational 
noise-exposed population for which the maximum acceptable occupational hearing loss will be (OSHA 2003). In addition, OSHA believes that the 5-dB exchange rate will account for any interruptions in noise exposures that commonly occur during the workday.

OSHA's regulation has an additional requirement for an action level (AL) of $85 \mathrm{dBA}$. In addition, during any 24-hour period, a worker can be exposed up to $100 \%$ of the daily noise dose (equivalent to $90 \mathrm{dBA}$ as an 8-hour TWA) and doses greater than $100 \%$ are considered to exceed the PEL (Harney et al. 2005). Commonly used noise exchange rates incorporate either a $3 \mathrm{~dB}$ or a $5 \mathrm{~dB}$ per doubling or halving of exposure duration. OSHA requires that every employer must administer a continuing and effective hearing conservation program (HCP) for all employees exposed to noise above to $85 \mathrm{dBA}$ during an 8-hour workday. According to OSHA, all workers exposed to noise at or above $85 \mathrm{dBA}$ as an 8hour TWA must be informed about the potential consequences of noise exposure and the methods of preventing NIHL. The elements of the HCP must include noise exposure monitoring or assessment, employee notification, observation, audiometric testing, hearing protection training and routine record keeping.

$\mathrm{NIOSH}$ has recommended exposure levels require that audiometric monitoring be conducted on noise-exposed workers either at the end or late in their daily work shifts with a view to discovering and taking action to prevent permanent hearing loss. NIOSH's recommended standards or guidelines stipulate for a recommended exposure limit (REL) of $85 \mathrm{dBA}$ as an 8-hour TWA with 3 dBA exchange rate that is more firmly supported by scientific evidence when compared to the $5 \mathrm{dBA}$ required by OSHA (Harney et al. 2005). Additionally, NIOSH requires the use of engineering and administrative controls to reduce hazardous noise to acceptable levels and communicates the RELs to regulatory agencies such as OSHA and the entire occupational safety and health community. NIOSH defines engineering control as modifications or replacements of equipment, or related physical change at the noise source or along the transmission path (with the exception of hearing protectors) that reduced noise levels at the employee's ears (NIOSH 1996). In a 2016 report, the National Academies of Sciences called on government agencies to strengthen research efforts on population-based data on hearing loss in American adults (NAS 2016). Noise exposure assessments are conducted to: determine if noise levels in the workplace could potentially cause NIHL; establish compliance with noise regulations, standards or recommended guidelines; enhance an existing hearing conservation program; for legal purposes (worker's compensation claims); identify possible safety hazards (communication and detection of emergency alarms); and (6) complete special requests (Royster et al. 2003).

Firearms are a common source of noise and hazardous noise levels associated with NIHL commonly occurs in the military and the police force during activities that involve firearm and pulse-induced explosions (Sulkowski et al. 2017). A number of studies have reported abnormal levels of noise exposures in various occupations, including construction workers, farmers, railway workers, civil aviation workers, military personnel, firefighters, shipyard workers, offshore workers, healthcare workers, musicians, and police officers (Guida et al. 2014, 
Win et al. 2015). Previously published studies of hazardous noise exposures have focused on conventional occupations such as airport grounds staff and military personnel, while only a few studies have targeted less obvious professions such as police officers (Lesage et al. 2009). The discharge of firearms constitutes a major source of routine noise among police officers during the course of their work shift. In a recent study of police officers in Brazil, Guida et al. (2014) reported noise levels that exceeded the national occupational health standards.

The weapons used routinely by police officers such as small caliber weapons, typically emit hazardous noise levels that ranged from 140 to $160 \mathrm{dBA}$ (Murphy and Tubbs 2007). Such high noise levels have the potential to cause hearing loss, which is a significant hazard in a number of populations, including military personnel, police officers, and recreational shooters (Pawlaczyk-Luszczynska et al. 2004, Wu and Young 2009). Police officers, when compared to the military, use the same or similar weapons which produce hazardous noise levels (Lindblad et al. 2011, Muhr and Rosenhall 2011), and also have similar requirements to maintain proficiency with various weapons (Murphy and Tubbs 2007). Considering that the risk of NIHL is often higher in the military than other occupational sectors, the incidence of service-related NIHL for police officers is reported to be similar to those of the military (Murphy and Tubbs 2007). This is in part due to the similarity in routine noise exposures from gunfire during normal work conditions or practice rounds at a shooting range.

In this study, we measured both personal and area noise levels associated with shotgun and rifle qualifications at an outdoor shooting range and compared them to the occupational exposure standards and guidelines designed to protect against noise-induced hearing loss. The main purpose of the study was to conduct a noise exposure assessment among police officers at a university in South-central Kentucky with a view to developing an intervention program to prevent or control the development of noise-induced hearing loss. Specifically, the objective was to determine personal and area noise levels, to compare recorded noise levels to OSHA noise standards, and to provide recommendations for the establishment of an effective hearing conservation program for police officers who may potentially be at risk of developing NIHL.

\section{Methodology}

\section{Study Design}

A noise exposure assessment was conducted among 19 law enforcement officers at a university, including 17 police officers and 2 instructors. Personal and area noise measurements were made during shotgun and rifle qualification rounds at an outdoor firing range. Personal noise measurement involved the officers having dosimeters equipped with microphones attached to their waistbands throughout the entire process. On the other hand, area noise measurements involved the use of handheld Sound Level Meters (SLM) by the investigators to measure sound levels at various distances from the police officers during the 
process. Qualification is an annual process through which police officers are tested and certified to carry and use firearms in accordance with standard proficiency levels. In this study, the police officers were subjected to qualifications that involved the use of both shotguns and rifles.

Personal and area noise monitoring was conducted over a period of three days during the summer of 2009. During the shotgun qualifications, 17 police officers and their 2 instructors were included in the study to determine their personal noise exposure measurements. For the rifle qualification, 8 police officers and 2 instructors selected from the same pool of the original 19 officers were included in personal noise measurements. Area or environmental noise measurements were also taken during both shotgun and rifle qualifications.

\section{Equipment Description and Noise Measurement Procedure}

Personal noise measurements were made using Quest ${ }^{\mathrm{TM}} 400$ noise dosimeters (Figure 1) (Quest Technologies 2010). The Quest ${ }^{\mathrm{TM}} 400$ noise dosimeters have data logging capabilities and were programmed to measure time weighted average (TWA), average noise level (Lavg), maximum and peak noise levels, and dose. Area noise measurements were made using Quest ${ }^{\mathrm{TM}} 2400$ Sound Level Meters (SLM). The noise dosimeters and SLM were calibrated before and after each measurement period. All sampling was conducted in accordance with the noise monitoring requirements stipulated in the OSHA Noise Standard as 29 CFR 1910.95 (OSHA 2003). All the police officers and instructors included in this noise survey were informed of the purpose and procedures for this assessment. The participants wore two types of hearing protection devices (HPDs): David Clark 10A Green Hearing Protector (Part \#: 12451G-01) and Silentio Hearing Protection. All noise dosimeters were attached to the waistband of the participants and the microphones were clipped to their shirt collars within the hearing zones.

Personal noise assessment was conducted with calibrated noise dosimeters during shotgun qualifications on Day 1 while 10 personal noise samples were collected during rifle qualifications on Day 2. Noise samples were collected during the morning and afternoon sessions. The dosimeters were turned on shortly before the qualification rounds started and paused in between rounds. The dosimeters worn by the instructors remained on throughout the sampling period. For area (environmental) measurements, samples were collected at various distances and positions from the target, including 25 yards from prone position; 15 yards from kneeling position; 7 yards, 5 yards, and 2 yards, from standing positions for shotgun. Individual data from the dosimeters were recorded manually and subsequently downloaded onto a computer as using excel spreadsheet in Quest Suite Professional Application Software ${ }^{\mathrm{TM}}$. The following parameters were recorded: time in minutes, average noise level (Lavg, (dBA), Maximum noise (dBA), and the Dose (\%).

The same protocols for personal noise measurement applied during shotgun qualifications were repeated during rifle qualifications. The police officers shot from the following distances and positions: 50 yards from prone position; 35 yards from prone, kneeling and standing positions; 25 yards from kneeling and standing 
positions; 15 yards from standing position; and 7 yards from standing position. The same parameters recorded for shotgun qualifications were also recorded during rifle qualifications. Area noise measurements were made using the SLM, which was used to measure instantaneous noise levels. The measurements were made at a height of approximately 3.0 feet from the ground, with a 1.5 feet distance from the shooters (i.e., using the same five distances and positions as described above for both shotgun and rifle qualifications). A total of 20 area noise samples (10 samples during shotgun and 10 samples during rifle) were recorded as average noise levels (dBA).

\section{Data Analysis}

All data collected with personal noise dosimeters and SLMs were downloaded onto a personal laptop computer using the Quest Suite Professional software $^{\mathrm{TM}}$ and saved for further analysis. Statistical analysis was conducted using GraphPad Prism version 7.02 and IBM Statistical Package for Social Sciences (SPSS) version 19. The noise exposure results for all participants were analyzed and both the mean and standard deviations were calculated. Unpaired t-test was used to compare means for different parameters for shotgun and rifle qualifications.

\section{Results}

\section{Personal Noise Exposure Using Shotgun}

The results of personal noise exposures during shotgun qualifications are shown in Table 1 and summarized in Figures 1 and 3. The Lavg was $94 \mathrm{dBA}$ (range $=74$ to $101 \mathrm{dBA}, \mathrm{SD}=5.4$ ). The Maximum SPL was $121 \mathrm{dBA}$ (range $=102$ to $127 \mathrm{dBA}, \mathrm{SD}=4.9$ ). The results showed that all police officers had Lavg that were above the of $90 \mathrm{dBA}$ averaged over an 8-hour period. The Maximum SPL reported for all participants was greater than $100 \mathrm{dBA}$, but less than of $140 \mathrm{dBA}$ (the impact noise standard). The reported Dose for all police officers were below $50 \%$, except for one instructor with a Dose of $54.4 \%$. In addition, there was a strong correlation $(\mathrm{R}=.838)$ between Lavg and Maximum SPL. However, as shown in Figure 1, there was a weak correlation between Lavg and Dose $(\mathrm{R}=.277)$ as well as between Maximum SPL and Dose ( $\mathrm{R}=.546)$.

\section{Personal Noise Exposure Using Rifle}

The results of personal noise exposures during rifle qualifications are shown in Table 2 and summarized in Figures 2 and 3. The average SPL was 94 dBA (range $=90$ to $101 \mathrm{dBA}, \mathrm{SD}=2.9$ ). All the recordings for Lavg were above $90 \mathrm{dBA}$. The Maximum SPL was $120 \mathrm{dBA}$ (range=117 to $123 \mathrm{dBA}, \mathrm{SD}=2.2$ ). The overall Dose recordings for both shotgun and rifle were below 50\% (Table 4). In addition, all the participants were exposed to average noise levels (Lavg) greater than 90 
$\mathrm{dBA}$. The results showed that with the exception of one instructor who had a Dose of $95.6 \%$, the Dose reported for all the police officers were below $50 \%$. The maximum noise exposure for all participants was greater than $100 \mathrm{dBA}$, but below OSHA's impact noise standard of $140 \mathrm{dBA}$. The unpaired t-test analysis showed a significant difference in Dose for shotgun when compared with riffle (Figure 3). However, both the Lavg and Maximum SPL were identical for both shotgun and rifle qualifications.

Table 1. Personal Noise Exposures of Police Officers during Shotgun Qualifications

\begin{tabular}{|c|c|c|c|c|}
\hline $\begin{array}{c}\text { Sample } \\
\text { Number }\end{array}$ & $\begin{array}{c}\text { Time } \\
\text { (minutes) }\end{array}$ & $\begin{array}{l}\text { Lavg } \\
\text { (dBA) }\end{array}$ & $\begin{array}{c}\text { Maximum } \\
(\text { dBA })\end{array}$ & Dose (\%) \\
\hline 01 & $28: 36$ & 95.6 & 122.9 & 26.0 \\
\hline 02 & $26: 56$ & 96.8 & 124.0 & 26.8 \\
\hline 03 & $24: 33$ & 96.4 & 123.8 & 24.8 \\
\hline 04 & $24: 59$ & 96.1 & 122.3 & 24.3 \\
\hline 05 & 103:37 & 91.7 & 127.0 & 54.4 \\
\hline 06 & 12.36 & 96.7 & 119.4 & 15.4 \\
\hline 07 & $23: 27$ & 98.9 & 126.2 & 16.7 \\
\hline 08 & $24: 11$ & 73.6 & 102.2 & 1.0 \\
\hline 09 & $25: 05$ & 91.5 & 118.8 & 6.4 \\
\hline 10 & $24: 33$ & 92.8 & 121.6 & 15.2 \\
\hline 11 & $25: 21$ & 96.0 & 122.9 & 12.1 \\
\hline 12 & $23: 27$ & 96.6 & 123.7 & 12.1 \\
\hline 13 & $19: 53$ & 93.3 & 121.1 & 13.1 \\
\hline 14 & 19.27 & 95.6 & 122.5 & 8.8 \\
\hline 15 & $16: 24$ & 101.3 & 119.6 & 16.3 \\
\hline 16 & $41: 32$ & 91.3 & 119.5 & 10.4 \\
\hline 17 & 18.44 & 95.4 & 122.1 & 8.2 \\
\hline 18 & $21: 50$ & 91.6 & 119.5 & 5.7 \\
\hline 19 & 20.39 & 96.2 & 123.1 & 10.2 \\
\hline 20 & $50: 31$ & 93.5 & 123.2 & 17.1 \\
\hline 21 & 49:51 & 91.3 & 121.0 & 12.4 \\
\hline 22 & $72: 36$ & 88.1 & 116.1 & 11.6 \\
\hline $\begin{array}{c}\text { OSHA } \\
\text { Standard }^{\mathrm{i}}\end{array}$ & 480 & $\begin{array}{c}\text { PEL }=90 \\
\text { AL }=85\end{array}$ & 140 & $\begin{array}{c}100 \text { (PEL @ } 90 \text { dBA) } \\
50 \text { (AL @ } 85 \text { dBA })\end{array}$ \\
\hline
\end{tabular}

Note: ${ }^{1}$ Instructor; OSHA Noise Standards: $\mathrm{PEL}=90 \mathrm{dBA}, \mathrm{AL}=85 \mathrm{dBA}$, Impact Noise $=140$ $\mathrm{dBA}$, Dose $=50 \%$. 
Vol. 6, No. $1 \quad$ Iyiegbuniwe et al.: Noise Exposure Assessment for University Police...

Figure 1. Noise Exposure Assessment for Police Officers during Shotgun Qualifications

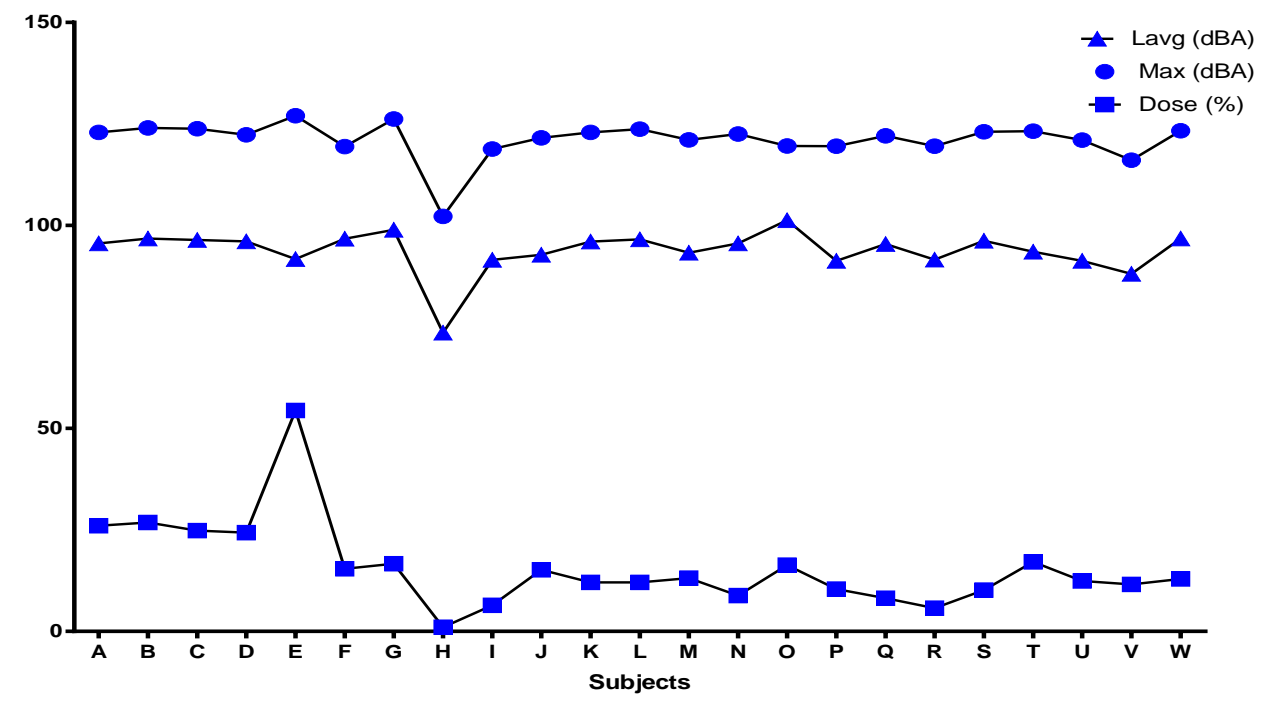

Note: The noise parameters measured included average sound pressure level (Lavg, dBA), maximum sound pressure level (Max SPL, dBA), and Dose (D, \%). "R" represents the Pearson correlation coefficient between two variables (Lavg vs. Max SPL, Lavg vs. Dose, and Max SPL vs. Dose).

Figure 2. Noise Exposure Assessment for Police Officers during Rifle Qualifications

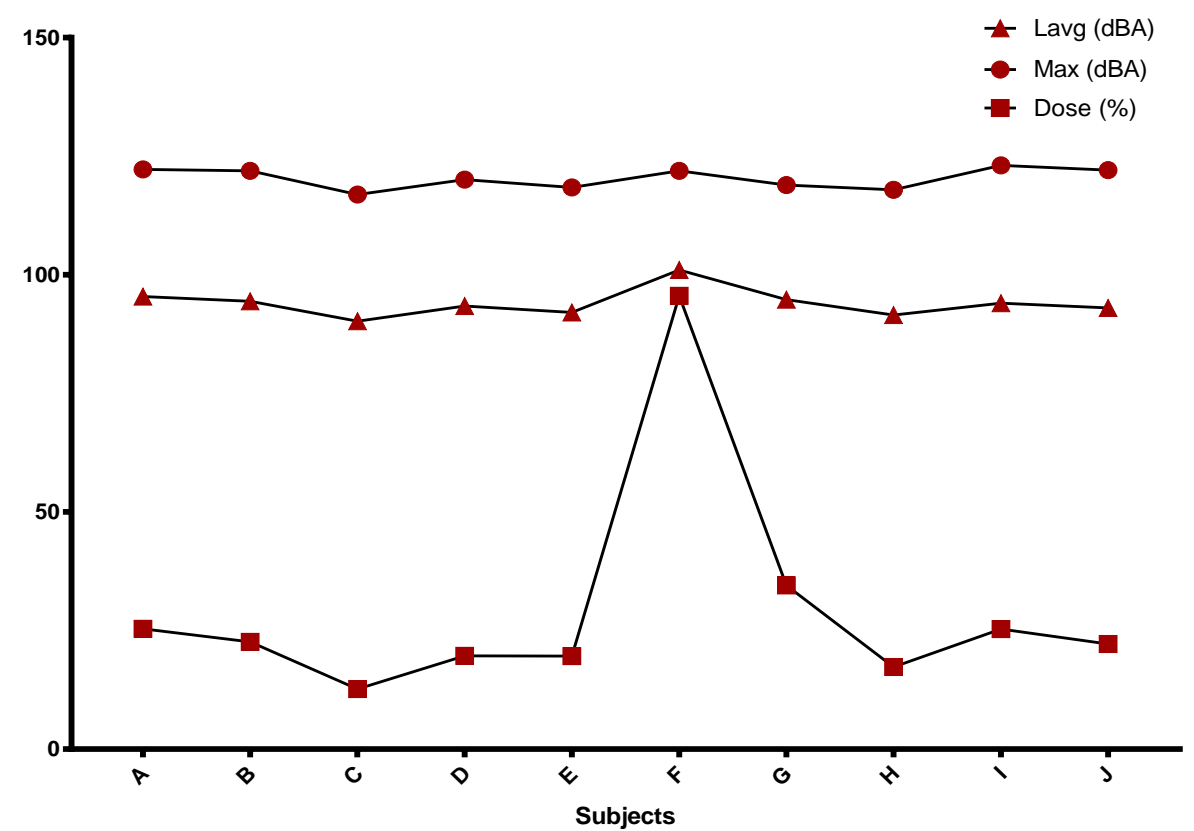


Table 2. Personal Noise Exposure Levels for Police Officers during Rifle Qualification

\begin{tabular}{|c|c|c|c|c|}
\hline $\begin{array}{c}\text { Sample } \\
\text { Number }\end{array}$ & $\begin{array}{c}\text { Time } \\
\text { (minutes) }\end{array}$ & $\begin{array}{c}\text { Lavg } \\
(\mathbf{d B A})\end{array}$ & $\begin{array}{c}\text { Maximum } \\
(\mathbf{d B A})\end{array}$ & Dose (\%) \\
\hline 01 & $57: 54$ & 95.4 & 122.2 & 25.4 \\
\hline 02 & $59: 14$ & 94.4 & 121.9 & 22.6 \\
\hline 03 & $59: 29$ & 90.2 & 116.9 & 12.7 \\
\hline 04 & $59: 05$ & 93.4 & 120.1 & 19.7 \\
\hline 05 & $70: 10$ & 92.1 & 118.4 & 95.6 \\
\hline $06^{\mathrm{i}}$ & $100: 18$ & 101 & 121.9 & 34.5 \\
\hline $07^{i}$ & $85: 16$ & 94.8 & 118.9 & 17.3 \\
\hline 08 & $67: 29$ & 91.5 & 117.9 & 25.3 \\
\hline 09 & $69: 59$ & 94.0 & 123.1 & 22.2 \\
\hline 10 & $70: 43$ & 93.0 & 121.1 & $\mathbf{1 0 0}$ (PEL @ 90 dBA) \\
\hline $\begin{array}{c}\text { OSHA } \\
\text { Standard }\end{array}$ & $\mathbf{4 8 0}$ & $\begin{array}{c}\text { PEL=90 } \\
\text { AL }=\mathbf{8 5}\end{array}$ & $\mathbf{1 4 0}$ & $\mathbf{5 0}$ (AL @ 85 dBA) \\
\hline
\end{tabular}

Note: ${ }^{\mathrm{i}}$ Instructor; OSHA Noise Standards: PEL $=90 \mathrm{dBA}, \mathrm{AL}=85 \mathrm{dBA}$, Impact Noise $=140$ $\mathrm{dBA}$, Dose $=100 \%(\mathrm{PEL}=90 \mathrm{dBA})$ and $50 \%(\mathrm{AL}=85 \mathrm{dBA})$.

Figure 3. Summary Personal Noise Exposure Levels during Shotgun and Rifle Qualifications

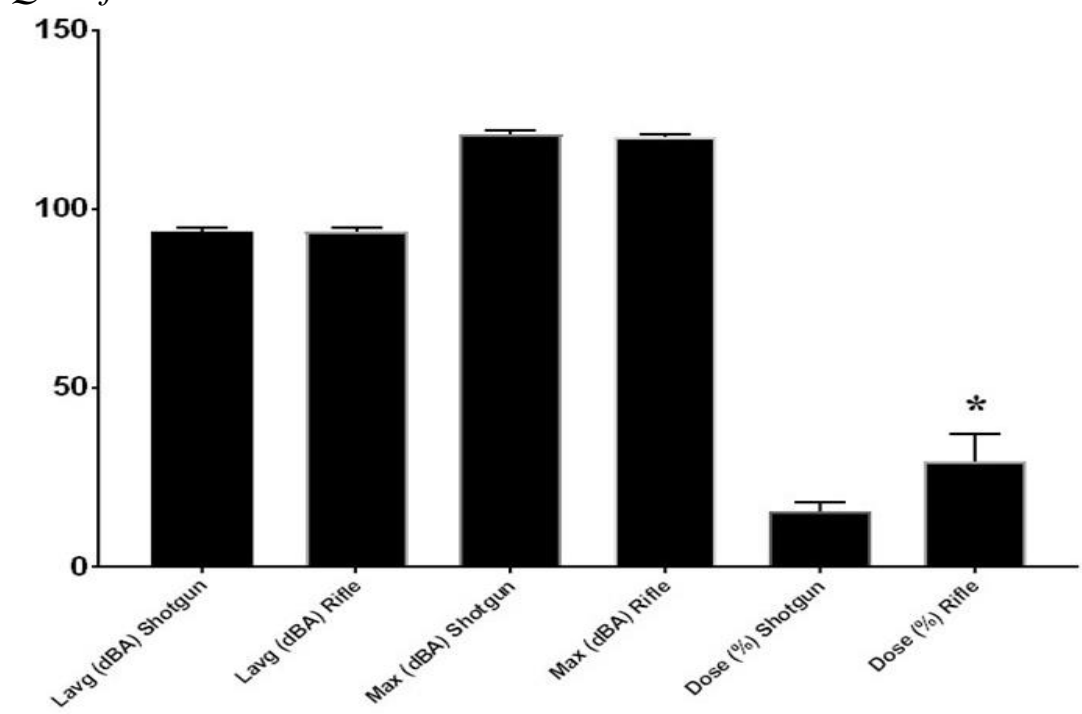

Note: $\mathrm{N} \geq 10 ; *$ indicates $\mathrm{p}<0.05$ vs. rifle by unpaired T-test.

Area (Environmental) Noise Levels for Shotgun and Rifle Qualifications

Tables 3, 4, and 5 provide the detailed and summary results of area or environmental noise levels for both shotgun and rifle qualifications. The reported parameters were shooting distance from the target, range, and the average SLM for both morning (am) and afternoon (pm) qualifications. The overall average noise levels from various distances to the target during the qualification rounds for shotgun ranged from $84.6 \mathrm{dBA}$ to $118.3 \mathrm{dBA}$ (morning) and 101.2 dBA to 120.3 dBA (afternoon). The overall average noise levels from various distances to the 
target during the qualification rounds for rifle ranged from $97.3 \mathrm{dBA}$ to $116.6 \mathrm{dBA}$ (morning) and $101.7 \mathrm{dBA}$ to $116.6 \mathrm{dBA}$ (afternoon). The data showed that there was an inverse relationship between distances and area noise levels for both shotgun and rifle. As illustrated in Figures 4, 5, and 6, the area noise levels increased as the distances between the shooters and their targets decreased.

Figure 4 showed that there was a significant difference in the area noise levels for shotgun between 2 yards and 25 yards. Furthermore, using unpaired t-tests for the data collected during rifle qualifications, there was a significant difference in reported noise levels between 7 yards and 50 yards as well as between 15 yards and 50 yards (Figure 5). However, as shown in Figure 6, no statistically significant difference existed between shotgun and rifle at 7, 15, and 25 yards.

Table 3. Area Noise Levels for Police Officers during Shotgun and Rifle Qualifications

\begin{tabular}{|c|c|c|c|c|}
\hline Description & Sample & $\begin{array}{c}\text { Distance } \\
\text { (Yard Line) }\end{array}$ & $\begin{array}{l}\text { Range } \\
\text { (dBA) }\end{array}$ & $\begin{array}{c}\text { Avg. SLM } \\
\text { (dBA) }\end{array}$ \\
\hline \multicolumn{5}{|c|}{ Shotgun: Morning } \\
\hline \multirow[t]{5}{*}{ Shooter 1} & 01 & 25 & $93.5-98.1$ & 96.1 \\
\hline & 02 & 15 & $96.9-100.4$ & 99.5 \\
\hline & 03 & 7 & $84.6-110.5$ & 102.0 \\
\hline & 04 & 5 & $111.1-114.5$ & 113.1 \\
\hline & 05 & 2 & $110.4-114.0$ & 112.7 \\
\hline \multirow[t]{5}{*}{ Shooter 2} & 06 & 25 & $101.0-110.6$ & 106.8 \\
\hline & 07 & 15 & $110.1-114.5$ & 112.4 \\
\hline & 08 & 7 & $108.9-116.3$ & 114.2 \\
\hline & 09 & 5 & $116.5-117.0$ & 116.7 \\
\hline & 10 & 2 & $117.2-118.3$ & 118.0 \\
\hline \multicolumn{5}{|c|}{ Shotgun: Afternoon } \\
\hline \multirow[t]{5}{*}{ Shooter 1} & 01 & 25 & $101.2-108.5$ & 105.7 \\
\hline & 02 & 15 & $109.0-113.2$ & 111.4 \\
\hline & 03 & 7 & $110.7-116.1$ & 113.8 \\
\hline & 04 & 5 & $113.8-117.8$ & 116.2 \\
\hline & 05 & 2 & 115.9-119.4 & 117.4 \\
\hline \multirow[t]{5}{*}{ Shooter 2} & 06 & 25 & 105.9-109.7 & 107.6 \\
\hline & 07 & 15 & 110.5-114.4 & 113.5 \\
\hline & 08 & 7 & $115.2-116.9$ & 116.2 \\
\hline & 09 & 5 & $111.0-117.1$ & 115.3 \\
\hline & 10 & 2 & $119.4-120.3$ & 119.8 \\
\hline \multirow[t]{5}{*}{ Rifle: Morning } & 01 & 50 & $103.2-107.4$ & 105.6 \\
\hline & 02 & 35 & $105.4-110.9$ & 108.9 \\
\hline & 03 & 25 & $105.0-110.6$ & 108.1 \\
\hline & 04 & 15 & $110.8-113.9$ & 113.0 \\
\hline & 05 & 7 & $109.3-116.6$ & 114.3 \\
\hline \multirow[t]{5}{*}{ Rifle: Afternoon } & 01 & 50 & $101.7-111.1$ & 106.4 \\
\hline & 02 & 35 & $109.7-111.0$ & 110.6 \\
\hline & 03 & 25 & $105.7-116.5$ & 111.4 \\
\hline & 04 & 15 & $110.4-114.8$ & 112.3 \\
\hline & 05 & 7 & $112.1-115.4$ & 113.9 \\
\hline
\end{tabular}


Figure 4. Area Noise Levels for Shotgun at Various Distances from the Shooter

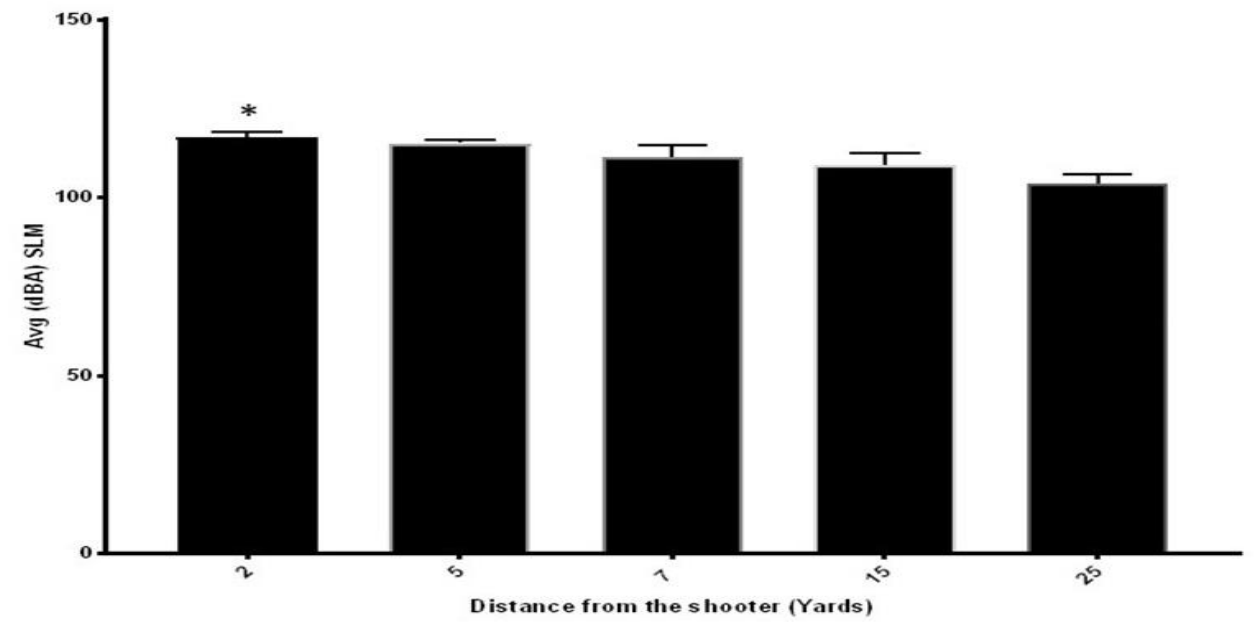

Note: $\mathrm{N}=4$; * indicates $\mathrm{p}<0.05$ vs. 25 yards using One-way ANOVA followed by Bonferroni correction for multiple comparisons.

Table 4. Personal Noise Exposure Levels during Shotgun and Rifle Qualifications

\begin{tabular}{|l|c|c|c|c|}
\hline Description & N & Mean (dBA) & Range (dBA) & SD \\
\hline Shotgun & & & & \\
\hline Lavg & 22 & 94 & $74-101$ & 5.38 \\
\hline Max SPL & 22 & 124 & $102-127$ & 4.88 \\
\hline Rifle & 10 & 94 & $90-101$ & 2.93 \\
\hline Lavg & 10 & 120 & $117-123$ & 2.18 \\
\hline Max SPL & $\begin{array}{c}\text { PEL=90 } \\
\text { AL=85 }\end{array}$ & Impact=140 & \\
\hline $\begin{array}{c}\text { OSHA Standards } \\
\text { (8-hour TWA) }\end{array}$ & & &
\end{tabular}

Figure 5. Area Noise Levels for Rifle at Various Distances from the Shooter

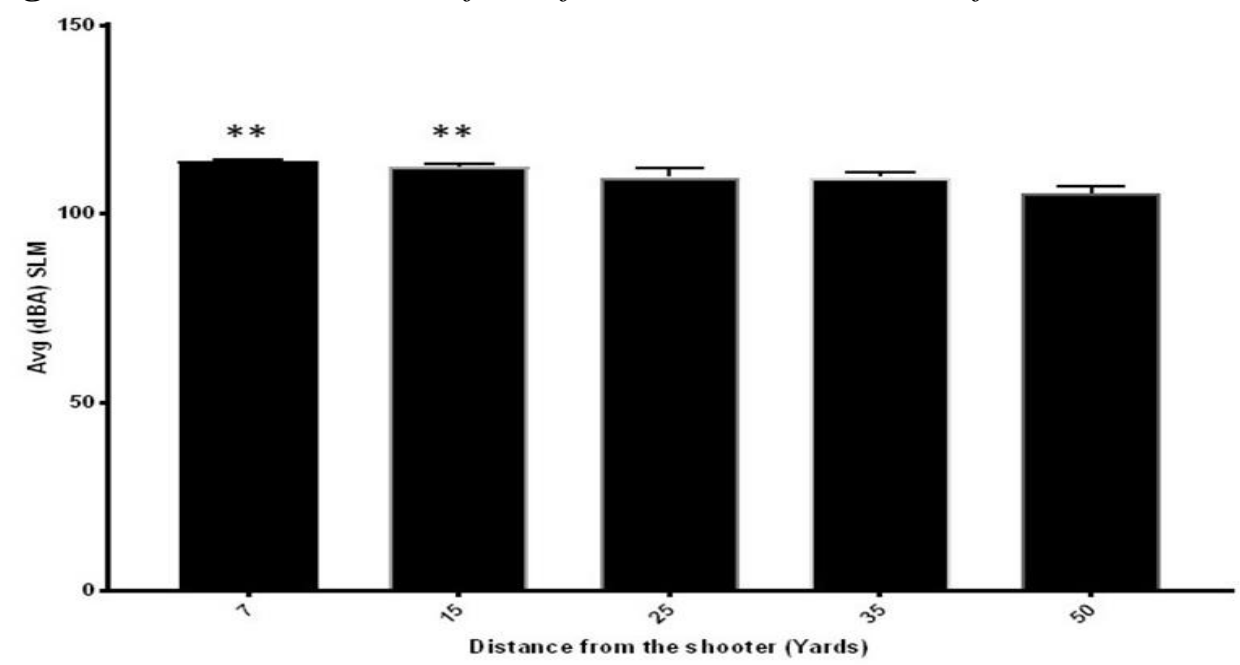

Note: $\mathrm{N} \geq 2$. ${ }^{*}$ indicates $\mathrm{p}<0.05$ vs. 50 yards by one-way ANOVA followed by Bonferroni correction for multiple comparisons. 
Vol. 6, No. $1 \quad$ Iyiegbuniwe et al.: Noise Exposure Assessment for University Police...

Table 5. Summary Area Noise Levels during Shotgun and Rifle Qualifications

\begin{tabular}{|l|c|c|c|c|}
\hline Description & $\mathbf{N}$ & Mean (dBA) & Range (dBA) & SD \\
\hline Shotgun & 10 & 116 & $107-121$ & 4.53 \\
\hline Rifle & 10 & 111 & $106-114$ & 2.61 \\
\hline Shotgun and Rifle & 20 & 112 & $106-121$ & 3.34 \\
\hline
\end{tabular}

Figure 6. Noise Levels for Shotgun and Rifle Compared at 7, 15 and 25 Yards from the Target

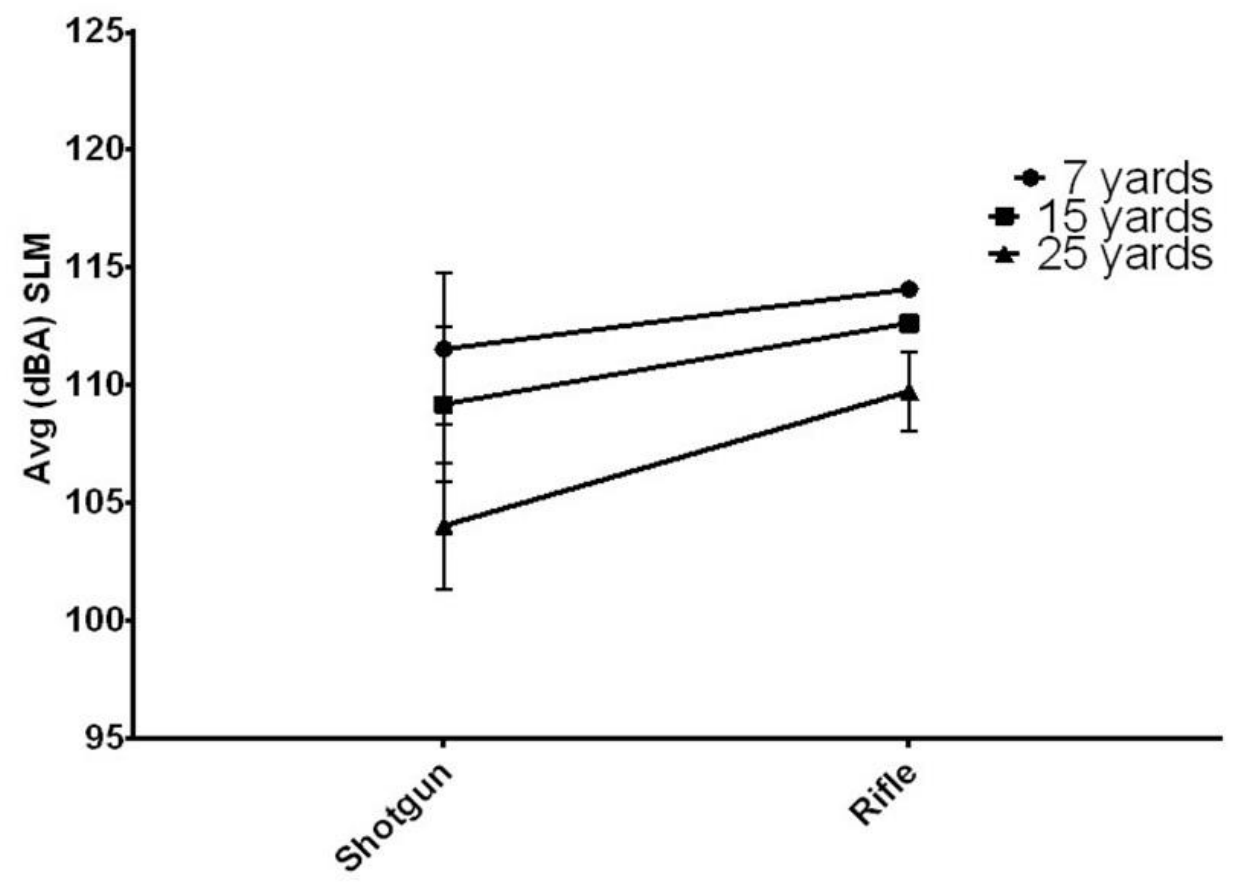

\section{Discussion}

Firearm-Associated Sound Pressure Levels and Noise Standards

The overall objective of the study was to determine personal noise exposure levels during shotgun and rifle qualifications for a representative sample of 17 police officers and 2 instructors at a university in South-central Kentucky. The OSHA standard for occupational noise exposure (29 CFR 1910.95) specifies a PEL of $90 \mathrm{dBA}$ averaged over an 8-hour time period using an exchange rate of 5 dBA (time/intensity relationship). The OSHA standard also specifies that exposure to impulse or impact noise should not exceed $140 \mathrm{dBA}$ (OSHA 2003). The results of personal noise exposure levels for shotgun showed the mean Lavg was $94 \mathrm{dBA}$ (range $=74$ to $101 \mathrm{dBA}, \mathrm{SD}=5.4$ ). With the exception of one police officer and one instructor, all the Lavg were above OSHA's PEL of $90 \mathrm{dBA}$ (Table 1). The results for rifle qualifications showed Lavg of $94 \mathrm{dBA}$ (range $=90$ to $101 \mathrm{dBA}, \mathrm{SD}=2.9$ ) and all exceeded OSHA's PEL of $90 \mathrm{dBA}$.

The mean Maximum SPL for shotgun was $121 \mathrm{dBA}$ (range $=102$ to $127 \mathrm{dBA}$, $\mathrm{SD}=4.9$ ) and all the readings were above $100 \mathrm{dBA}$, but none below OSHA's 
impact noise standard of $140 \mathrm{dBA}$. The mean Maximum SPL was $120 \mathrm{dBA}$ (range=117 to $123 \mathrm{dBA}, \mathrm{SD}=2.2$ ). The Maximum SPLs measured during shotgun and rifle qualifications were below $140 \mathrm{dBA}$. In addition, the Maximum SPL from this study were below those previously reported in the literature for similar small caliber weapons used during training and leisure time activities by Murphy and Tubbs (2007) and Pawlaczyk-Luszczynska et al. (2004) with noise levels that ranged from 156 to $170 \mathrm{dBA}$ and 132 to $165 \mathrm{dBA}$, respectively. These previous studies reported maximum SPLs that generally exceeded the OSHA's impulse noise standard of $140 \mathrm{dBA}$. This may be due in part to the fact that this study was conducted in an isolated outdoor shooting range in a remote location surrounded by dense vegetation where sound levels often had adequate space to dissipate or be absorbed. Several of the studies reviewed for comparison were conducted in indoor settings or shooting ranges (Wu and Young 2009, Murphy and Tubbs 2007, Pawlaczyk-Luszczynska et al. 2004) and this may provide some explanation for the higher noise levels previously reported.

It is important to note that the results presented in this study cannot be generalized to suggest that the 17 police officers and 2 instructors were at minimum risks of developing NIHL or other related adverse health effects of hazardous noise exposure. In addition, no audiometric testing or assessment was conducted for all the police officers included in this study. The prevalence of NIHL among police officers is high, remains a significant health impact of occupational firearm use, and often associated with physiological and pathological factors as well as the duration of service and rank of the affected police officer (Win et al. 2015, Moon et al. 2011). Virkkunen et al. (2005) reported that continuous and impulse noise exposures greater than $80 \mathrm{dBA}$ was associated with increased risks of coronary heart disease. In addition, several studies have documented that over-exposures to hazardous noise was associated with significant hearing losses, tinnitus, irritability, sleep disturbance, and exacerbation of hypertension and cardiovascular diseases (Chang et al. 2003, PasschierVermeer and Passchier 2000, Stansfeld et al. 2000, Virkkunen et al. 2005). Additionally, loss of hearing has been associated with adverse psychological effects with decreased job performance and productivity (Vaillancourt et al. 2011).

Area or environmental noise levels for both shotgun and rifle (Table 5) showed that the average SLM were $112 \mathrm{dBA}$ (range=106 to $21 \mathrm{dBA}, \mathrm{SD}=3.4$ ) and $116 \mathrm{dBA}$ (range=107 to $121 \mathrm{dBA}, \mathrm{SD}=4.5$ ) for shotgun and $111 \mathrm{dBA}$ (range=106 to $14 \mathrm{dBA}, \mathrm{SD}=2.6$ ) for rifle, respectively. All area or environmental sound levels were above $100 \mathrm{dBA}$ but below $140 \mathrm{dBA}$, the OSHA noise standard for impulse noise. Although previous studies have shown that rifles generally emit slightly higher noise levels than shotguns (Murphy and Tubbs 2007, PawlaczykLuszczynska et al. 2004), however, in this survey we reported that shotguns had slightly higher noise levels than rifles. The short duration of the sampling time for this study makes it difficult to make a broad statement on why this anomaly was observed, It must be noted that police officers often use several small caliber weapons such as rifles and shotguns, during their practice rounds (PawlaczykLuszczynska et al. 2004). Small caliber weapons were reported by previous studies to produce peak noise levels that exceeded both the OSHA's PEL and 
NIOSH's recommended exposure level of $140 \mathrm{~dB}$ for impulse noise (Murphy and Tubbs 2007, Pawlaczyk-Luszczynska et al. 2004).

\section{Noise-Induced Hearing Loss Associated with Firearms}

The numbers presented in these results were below those reported by NIOSH during a health hazard evaluation conducted on a Special Weapons Assault Team during indoor and outdoor weapons training with peak noise levels that ranged from 156 to $170 \mathrm{dBA}$ (Murphy and Tubbs 2007). Furthermore, guns, miniature rifles, and assault rifles used during training and even during leisure time can produce SPL with a range of 132 to $165 \mathrm{dBA}$ (Pawlaczyk-Luszczynska et al. 2004). Most previous studies on noise exposure assessments among law enforcement officers have focused on military personnel and their risks of developing NIHL as a result of their use of weapons (Collee et al. 2011, Lindblad et al. 2011, Mrena et al. 2009, Muhr and Rosenhall 2011). These studies are still relevant and comparable to police officers due to their use of similar weapons (Lindblad et al. 2011, Muhr and Rosenhall 2011) and their requirements of similar proficiency tests with various weapons (Murphy and Tubbs 2007, PawlaczykLuszczynska et al. 2004). Even though the military could be at greater risk of NIHL than other occupations, police officers have a similar incidence of servicerelated hearing loss when compared to other occupations (Murphy and Tubbs 2007). In general, there was not enough data on police officers' hearing thresholds and the risks of NIHL from exposure to hazardous occupational noise, in part because most previous studies focused on occupations with more obvious and documented cases of hazardous noise exposures (Lesage et al. 2009).

\section{Preventing Firearm-Associated Noise-Induced Hearing Loss}

Hearing protective devices (HPDs), such as earplugs or earmuffs, have been found to be effective in reducing noise levels to prevent NIHL and can effectively attenuate the peak SPL typically by as much as 25-35 dBA (Collee et al. 2011, Mrena et al. 2009, Muhr and Rosenhall 2011, Pawlaczyk-Luszczynska et al. 2004). In addition, doubling the HPDs by using both earplugs and earmuffs can further reduce the peak levels by an additional 15-20 dBA, resulting in over a 40 dBA reduction (Murphy and Tubbs 2007, Wu and Young 2009). Communication issues among officers, which further increases with double protection, may be solved by the use of electronic HPDs, such as electronic level limiting earmuffs (Murphy and Tubbs 2007). Some studies have emphasized the importance of proper and efficient training on earplug fit and insertion (Collee et al. 2011, Mrena et al. 2009, Muhr and Rosenhall 2011), and suggested the use of non-linear earplugs, and active noise reduction headsets (Collee et al. 2011). Hearing impairment would significantly decrease a police officer's ability to perform duties properly. Functional hearing is essential for successful task completion within occupations such as military, pilots, firefighters, and law enforcement (Vaillancourt et al. 2011). 


\section{Comparing Hearing Impairment Associated with Shotgun and Rifle}

Using unpaired t-tests to compare Lavg, Maximum noise levels, and Dose between the shotgun and rifle, our data showed that there was a significant difference in the Dose between the two types of firearms. Based on these results, the police officer may be in greater danger of noise-induced hearing loss using the rifle compared to the shotgun. However, there was not a significant difference between the Lavg for shotgun and the Lavg for rifle. Similarly, there was not a significant difference between the mean shotgun maximum SPL and the mean rifle Maximum SPL. This result may suggest that the rifle, being a larger caliber weapon, would have produced more sound as confirmed by other previous studies (Murphy and Tubbs 2007, Pawlaczyk-Luszczynska et al. 2004). However, another study suggested that small caliber guns often disrupted middle ear function, despite the use of ear plugs (Job et al. 2016), indicating that hearing protection should involve a more comprehensive process.

A comprehensive approach is especially vital because in addition to noise exposure, age, male gender, high blood pressure, diabetes and duration of service, are all significantly associated with noise-induced hearing loss among police officers (Win et al. 2015). Due to the number of recorded SPLs that were above 90 $\mathrm{dBA}$, and potential chronic exposure to such exposure levels, the results as a whole suggest that both police officers and instructors may be at risk of NIHL, regardless of whether they are using a rifle or a shotgun during their qualification rounds. Use of double hearing protection devices (HPDs) at all times during qualification rounds should be continued. NIHL is permanent, but preventable; hence, it is recommended that the University police officers and instructors continue to adhere to standard 29CFR 1910.95 (OSHA 2003). University police officers should have their noise exposure levels assessed for an entire 8-hour work shift that would incorporate their qualification rounds, and other daily work-related activities. This will provide a better idea and more realistic data for their typical noise exposure levels and hence enable to make adequate and informed statistical comparisons with the OSHA noise standards.

\section{Limitations of the Study}

This study has a number of limitations including that the data utilized had a small sample size that was not a random sample of police officers. Rather, data collection was from a convenient and representative sample of police officers and instructors who volunteered to participate in the study. This may provide some limitation to the statistical analysis and interpretation of the results of the study. In addition, the sampling times were of very short durations when compared to a typical 8-hour workday. It must be recognized that OSHA's noise standards (PEL and AL) are based on an 8 hour TWA. For an accurate comparison of the results of this study to OSHA's noise standards, one would have to collect noise dosimeter readings for a typical 8-hour work shift. However, extrapolation of the results of the study would be difficult. If we assume that the exposures had continued for an entire 8-hour work shift without hearing protection, the results 
obtained would have exceeded the OSHA's PEL and AL. This would suggest that the police officers and instructors included in the study were over-exposed to hazardous noise levels during both shotgun and rifle qualifications. There may be a presumption that the police officers and instructors were at increased risks for NIHL. However, based on the short duration of exposures and the results of this study, no such generalization can be made.

\section{Conclusion}

In this study, we assessed noise exposure among police officers at a University in South central Kentucky during routine rifle and shotgun qualifications at an outdoor firing range. In general, the personal exposure assessment revealed that the Lavg for both shotgun and rifle were similar (94 dBA). Without consideration of the duration of exposures, the data showed that 20 of the 22 personal noise levels (Lavg) exceeded OSHA's PEL of $90 \mathrm{dBA}$, but the maximum noise levels were below the impact noise standard of $140 \mathrm{dBA}$. The all but one of the 22 results of personal exposures exceeded $85 \mathrm{dBA}$, which is OSHA's Action Level that would trigger the mandatory implementation of a hearing conservation program for the police officers. In this regard, the use of adequate and effective hearing protection devices (i.e., a combination of ear plugs and muffs) is advised at all times during shotgun and rifle qualification for all police officers including those within close proximity from the shooters such as their instructors.

Occupational noise exposure remains an important, but often overlooked, risk factor for sensorineural hearing loss and other significant health outcomes. Hearing loss affects people psychologically and often leads to reduced job performance and productivity. A comprehensive strategy to prevent hearing loss should include efforts to reduce exposure to hazardous noise directly from the source, implementation of administrative controls, and the use of personal protective equipment. Noise-induced hearing loss can be minimized among law enforcement officers who routinely use firearms by instituting comprehensive and effective HCP. According to OSHA (2018), HCP "strive to prevent initial occupational hearing loss, preserve and protect remaining hearing, and equip workers with the knowledge and hearing protection devices necessary to safeguard themselves". The HCP includes the use of adequate hearing protection devices and other key elements that are critical for understanding and protecting the hearing of American workers in industries with hazardous noise.

\section{References}

Bhatt JM, Lin HW, Bhattacharyya N (2017) Epidemiology of Firearm and other Noise Exposures in the United States. Laryngoscope 127(10): E340-E346.

Bogardus ST, Jr, Yueh B, Shekelle PG (2003) Screening and Management of Adult Hearing Loss in Primary Care: Clinical Applications. JAMA 289: 1986-1990. 
Chang TY, Jain RM, Wang CS, Chan CC (2003) Effects of occupational Noise Exposure on Blood Pressure. Journal of Occupational and Environmental Medicine 45(12): 1289-1296.

Collee A, Legrand C, Govaerts B, Van Der Veken P, De Boodt F, Degrave E (2011) Occupational Exposure to Noise and the Prevalence of Hearing Loss in a Belgian military Population: A Cross-sectional Study. Noise Health 13(50): 64-70.

Concha-Barrientos M, Campbell-Lendrum D, Steenland K (2004) Occupational Noise: Assessing the Burden of Disease from Work-related Hearing Impairment at Nationaland Local Levels. WHO Environmental Burden of Disease Series. Geneva: World Health Organization.

Guida HL, Taxini CL, Goncalves CG, Valenti VE (2014) Evaluation of Hearing Protection used by Police Officers in the Shooting Range. Brazilian Journal of Otorhinolaryngology 80(6): 515-521.

Harney J, King B, Tubbs R, Crouch K, Hayden C, Kardous C. et al. (2005) HETA \#20000191-2960 Immigration and Naturalization Service (INS) National Firearms Unit (NFU) Altoona, Pennsylvania (2000-0191-2960). Retrieved from Cincinnati Ohio: https://www.cdc.gov/niosh/hhe/reports/pdfs/2000-0191-2960.pdf

Jansen EJ, Helleman HW, Dreschler WA, de Laat JA (2009) Noise induced Hearing Loss and other Hearing Complaints among Musicians of Symphony Orchestras. International Archives of Occupational and Environmental Health 82(2): 153-164.

Job A, Hamery P, De Mezzo S, Fialaire JC, Roux A, Untereiner M et al. (2016) Rifle Impulse Noise affects Middle-ear Compliance in Soldiers Wearing Protective Earplugs. International Journal of Audiology 55(1): 30-37.

Lesage FX, Jovenin N, Deschamps F, Vincent S (2009) Noise-induced Hearing Loss in French Police Officers. Occupational Medicine (London) 59(7): 483-486.

Lindblad AC, Hagerman B, Rosenhall U (2011) Noise-induced Tinnitus: A Comparison between Four Clinical Groups without Apparent Hearing Loss. Noise Health 13(55): 423-431.

Moon IS, Park SY, Park HJ, Yang HS, Hong SJ, Lee WS (2011) Clinical Characteristics of Acoustic Trauma caused by Gunshot Noise in Mass Rifle Drills without Ear Protection. Journal of Occupational and Environmental Hygiene 8(10): 618-623.

Mrena R, Savolainen S, Kiukaanniemi H, Ylikoski J, Makitie AA (2009) The Effect of tightened Hearing Protection Regulations on Military Noise-induced Tinnitus. International Journal of Audiology 48(6): 394-400.

Muhr P, Rosenhall U (2011) The Influence of Military Service on Auditory Health and the Efficacy of a Hearing Conservation Program. Noise Health 13(53): 320-327.

Murphy WJ, Tubbs RL (2007) Assessment of noise exposure for indoor and outdoor firing ranges. Journal of Occupational and Environmental Hygiene 4(9): 688-697.

Nandi SS, Dhatrak SV (2008) Occupational Noise-induced Hearing Loss in India. Indian Journal of Occupational and Environmental Medicine 12(2): 53-56.

NAS-National Academies of Sciences, Engineering, and Medicine (2016) Hearing Health Care for Adults: Priorities for Improving access and Affordability. Washington, DC: The National Academies Press.

NIOSH (1996) Preventing Occupational Hearing Loss-A Practical Guide. Cincinnati, OH: US Department of Health and Human Services, Public Health Service, Centers for Disease Control and Prevention, National Institute for Occupational Safety and Health, DHHS (NIOSH) Publication No. 96-110.

NIOSH (1998) Occupational Noise Exposure. Revised Criteria. Cincinnati, OH: US Department of Health and Human Services.

OSHA (2003) Occupational Noise Exposure (Vol. 29 CFR 1910.95). Washington, DC: US Department of Labor, Occupational Safety and Health Administration. 
OSHA (2018). Occupational Noise Exposure. Retrieved from https://www.osha.gov/ SLTC/noisehearing-conservation/.

Passchier-Vermeer W, Passchier WF (2000) Noise Exposure and Public Health. Environmental Health Perspective 108 Suppl 1: 123-131.

Patel VS, Ingle ST (2008) Occupational Noise Exposure and Hearing Loss among Pulse Processing Workers. Environmentalist 28(4): 358-365.

Pawlaczyk-Luszczynska M, Dudarewicz A, Bak M, Fiszer M, Kotylo P, SliwinskaKowalska M (2004) Temporary Changes in Hearing after Exposure to Shooting Noise. International Journal of Occupational Medicine and Environmental Health 17(2): 285-293.

Royster LH, Berger EH, Royster JD (2003) Noise Surveys and Data Analysis: Why Conduct a Sound Survey? In EH Berger, LH Royster, JD Royster, DP Driscoll, M Layne (Eds.), The Noise Manual (Revised 5th ed., pp. 168-170). Fairfax, VA: AIHA Press.

Stansfeld SA, Haines MM, Burr M, Berry B, Lercher P (2000) A Review of Environmental Noise and Mental Health. Noise Health 2(8): 1-8.

Sulkowski W, Owczarek K, Olszewski J (2017) Contemporary Noise-induced Hearing Loss (NIHL) Prevention. Otolaryngology Policy 71(4): 1-7.

Tak S, Calvert GM (2008) Hearing Difficulty Attributable to Employment by Industry and Occupation: An Analysis of the National Health Interview Survey-United States, 1997 to 2003. Journal of Occupational and Environmental Medicine 50: 46-56.

Vaillancourt V, Laroche C, Giguere C, Beaulieu MA, Legault JP (2011) Evaluation of Auditory Functions for Royal Canadian Mounted Police Officers. Journal of American Academy of Audiology 22(6): 313-331.

Virkkunen H, Kauppinen T, Tenkanen L (2005) Long-term Effect of Occupational Noise on the Risk of Coronary Heart Disease. Scandinavian Journal of Work and Environmenal Health 31(4): 291-299.

Win KN, Balalla NB, Lwin MZ, Lai A (2015) Noise-Induced Hearing Loss in the Police Force. Safety Health Work 6(2) 134-138.

Wu CC, Young YH (2009) Ten-year Longitudinal Study of the Effect of Impulse Noise Exposure from Gunshot on Inner Ear Function. International Journal of Audiology 48(9): 655-660. 